\title{
1,3-Dipolar Cycloaddition for the Generation of Nanostructured Semiconductors by Heated Probe Tips
}

\author{
Selma Bakbak ${ }^{\dagger}$, Peter J. Leech ${ }^{\dagger}$, Bradley Carson $^{\dagger}$, Shubham Saxena ${ }^{\ddagger}$, \\ William P. King ${ }^{* *}$, and Uwe H. F. Bunz ${ }^{\dagger *}$. \\ School of Chemistry and Biochemistry, and Woodruff School of Mechanical Engineering, \\ Georgia Institute of Technology, Atlanta, GA 30332.
}

\section{Numbering Scheme in Experimental is different from that in the manuscript}

\section{Experimental}

Instrumentation. The ${ }^{1} \mathrm{H}$ and ${ }^{13} \mathrm{C}$ NMR spectra were taken on a Varian $300 \mathrm{MHz}$. The ${ }^{1} \mathrm{H}$ chemical shifts are referenced to the residual proton peaks of $\mathrm{CDCl}_{3}$ at $\delta$ 7.24. The ${ }^{13} \mathrm{C}$ resonances are referenced to the central peak of $\mathrm{CDCl}_{3}$ at $\delta 77.0$ and. UV-VIS measurements were made with a Shimadzu UV-2401PC recording spectrophotometer. Fluorescence data was obtained with a Shimadzu RF-5301PC spectrofluorophotometer. 9,9-Didodecyl-9H-fluorene ${ }^{1}$, 2,7-diazido-9-H-fluorene ${ }^{2}$ and 4,4'-Diazido-3,3'-dimethoxy-biphenyl ${ }^{2}$ were synthesized and characterized in accordance to published procedures.
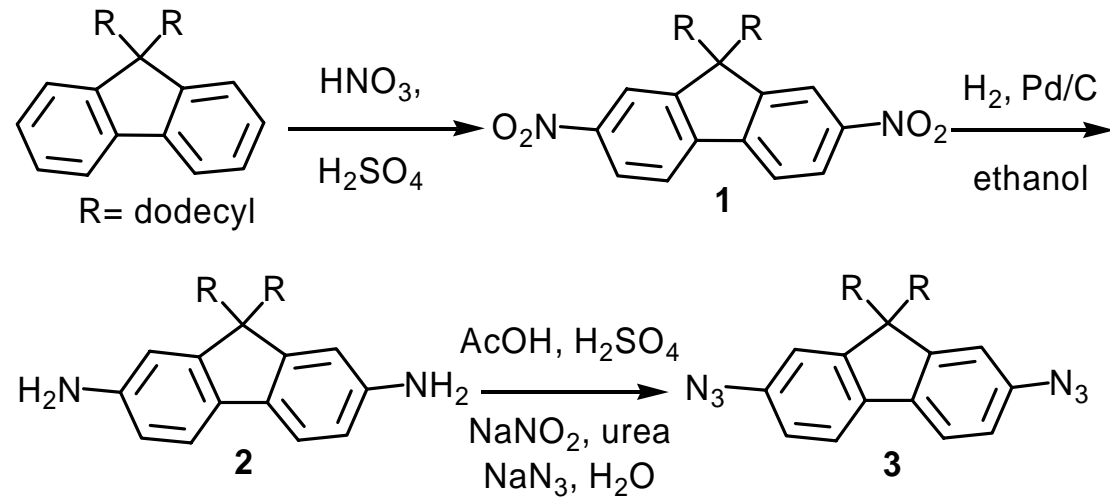

Scheme 1. Synthesis of the fluorene-diazide 3

9,9-Didodecyl-2,7-dinitro-9H-fluorene (1): In a $250 \mathrm{~mL}$ round bottom flask, 9,9-didodecyl-9Hfluorene (10.0 g, $19.9 \mathrm{mmol})$ was added to a mixture of concentrated sulfuric acid $(50.0 \mathrm{~mL})$ and fuming nitric acid $(50.0 \mathrm{~mL})$ at $0^{\circ} \mathrm{C}$. The mixture was stirred at room temperature for $2.5 \mathrm{~h}$ then reaction was stopped. The mixture was poured into ice-water and extracted with $\mathrm{CH}_{2} \mathrm{Cl}_{2}$ and water. The organic layer was dried over $\mathrm{MgSO}_{4}$ and the solvent removed. Product was collected as off-white solid $(11.8 \mathrm{~g}, 72 \%)$. ${ }^{1} \mathrm{H} \mathrm{NMR}\left(\mathrm{CDCl}_{3}\right): \delta 8.34,8.26,7.93,2.10,1.21-1.04,0.82$, $0.55 ;{ }^{13} \mathrm{C} \mathrm{NMR}\left(\mathrm{CDCl}_{3}\right): \delta 153.7,148.6,144.9,123.8,121.8,118.7,56.7,40.0,32.0,30.0,29.8$, 29.7, 29.4, 24.0, 22.8, 14.3; IR: v 3101, 3926, 2852, 1921, 1794, 1612, 1591, 1524, 1466, 1340, $1130,1072,899,831,785,739$.

9,9-Didodecyl-9H-fluorene-2,7-diamine (2): To a solution of 9,9-didodecyl-2,7-dinitro-9Hfluorene $(6.73 \mathrm{~g}, 80 \%)$ in ethanol $\mathrm{Pd} / \mathrm{C}$ catalyst $(0.30 \mathrm{~g})$ was added in a steel bomb. The vessel was pressurized and the pressure was released for 3 times. Finally the hydrogen bomb was filled 
with pressurized $\mathrm{H}_{2}$ (2000 psi) and the vessel was heated to $50{ }^{\circ} \mathrm{C}$ for 2 days. Reaction was stopped and solvent was evaporated. The mixture was filtered over celite, the filter cake was washed with $\mathrm{CH}_{2} \mathrm{Cl}_{2}$ then the filtrate was evaporated and dried. (5.73 g, 80\%, off-white solid).

${ }^{1} \mathrm{H} \mathrm{NMR}\left(\mathrm{CDCl}_{3}\right): \delta 7.35,6.63,6.61,3.59,1.84,1.21,1.06,0.90,0.68 ;{ }^{13} \mathrm{C} \mathrm{NMR}\left(\mathrm{CDCl}_{3}\right): \delta$ $115.8,144.8,133.3,119.3,114.1,110.3,54.8,41.2,32.2,30.5,30.0,29.8,29.6,29.5,24.0,23.0$, 14.4; IR: $v$ 3462, 3369, 3213, 2924, 2851, 1850, 1618, 1583, 1468, 1327, 1298, 1244, 1130, 858, $808 ; \mathrm{Mp}=56^{\circ} \mathrm{C}$.

2,7-Diazido-9,9-didodecyl-9H-fluorene (3): In a $500 \mathrm{~mL}$ round bottom flask, 9,9-dimethyl-9Hfluorene-2,7-diamine $(5.00 \mathrm{~g}, 9.38 \mathrm{mmol})$ was added to a mixture $40.0 \mathrm{~mL} \mathrm{AcOH}$ and $20.0 \mathrm{~mL}$ concentrated $\mathrm{H}_{2} \mathrm{SO}_{4}$. Then sodium nitrite $(1.38 \mathrm{~g}, 20.0 \mathrm{mmol})$ in $20.0 \mathrm{~mL}$ water was added drop wise to a mixture at $0^{\circ} \mathrm{C}$. After $10 \mathrm{~min}$ of stirring, urea was added to the mixture to remove excess sodium nitrite and finally sodium azide $(1.10 \mathrm{~g}, 20.0 \mathrm{mmol})$ was added. The reaction was stirred at $0^{\circ} \mathrm{C}$ for $3 \mathrm{~h}$. and mixture was poured into ice water. Aqueous sodium hydroxide was added and the mixture extracted with ethyl acetate. The organic layer was dried over $\mathrm{MgSO}_{4}$ and the solvent removed to give product as yellow solid $(5.11 \mathrm{~g}, 93 \%)$.

${ }^{1} \mathrm{H}$ NMR $\left(\mathrm{CDCl}_{3}\right): \delta 7.61,7.00,6.95,1.92,1.27-1.05,0.91-0.84,0.57 ;{ }^{13} \mathrm{C} \mathrm{NMR}\left(\mathrm{CDCl}_{3}\right): \delta$ $152.8,138.9,120.8,118.1,113.8,55.7,40.6,32.1,30.1,29.7,29.5,27.1,23.9,22.9$, 14.3; IR: $v$ 3204, 2924, 2851, 2401, 2100, 1859, 1610, 1581, 1462, 1441, 1375, 1294, 1140, 1090, 889, 804, 721,$669 ; \mathrm{Mp}=38{ }^{\circ} \mathrm{C}$.

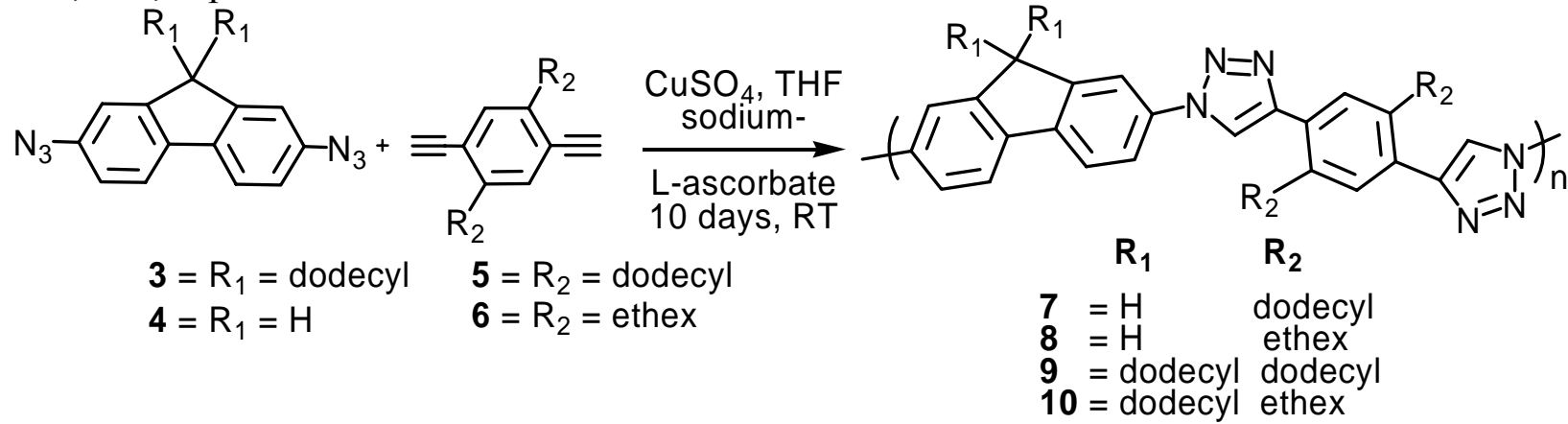

Scheme 2. Synthesis of the polymers 7-10

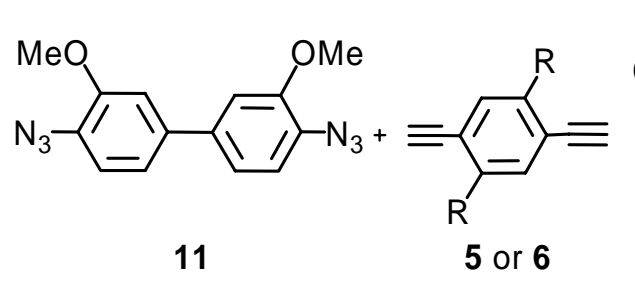

11

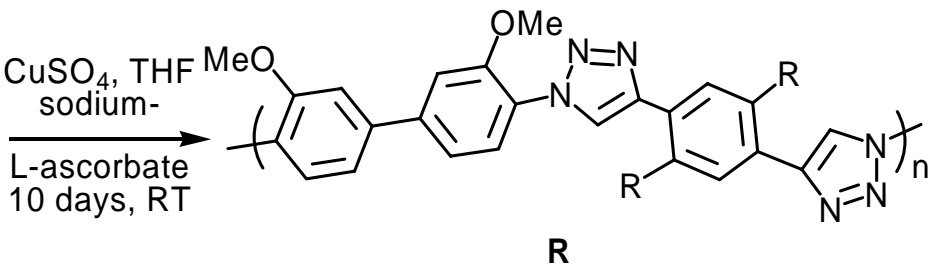

$12=$ dodecyl

$13=\mathrm{et} / \mathrm{hex}$

Scheme 2. Synthesis of the polymers 12 and $\mathbf{1 3}$

General Procedure for the Synthesis of the Polymers 7-13: Diethynyl and diazide monomers (1:1 equiv.) and sodium ascorbate $(5 \mathrm{~mol} \%)$ were dissolved in THF $(5 \mathrm{~mL})$ under flow of nitrogen into a flame dried Schlenk flask. The flask was flushed with flow of nitrogen for 15 min and the mixture was frozen and evacuated for three times and $\mathrm{CuSO}_{4}(5 \mathrm{~mol} \%)$ was added. The mixture was allowed to stir at ambient temperature for 5 days. The THF was removed under vacuum and the mixture was dissolved in dichloromethane, washed with $1 \mathrm{~N} \mathrm{HCl}, 1 \mathrm{~N} \mathrm{NH} \mathrm{NH}_{4}$, 
and water. The organic layer was dried over $\mathrm{MgSO}_{4}$ and the solvent removed. The resulting polymer was dissolved in chloroform and precipitated out of methanol.

Polymer 7: 0.142 g (92 \%), insoluble green-yellow solid. ${ }^{13} \mathrm{C}$ NMR (solid-state): $\delta=199.8$, $185.0,143.9,142.2$, 138.4, 134.4, 126.6, 118.3, 51.9, 29.3, 22.5, 13.7; IR: $v$ 3437, 2922, 2651, $1616,1461,1363,1225,1153,1034,808 ; \Phi_{\mathrm{F}}=0.29 ; \lambda \max _{\mathrm{abs}}=322, \lambda \max _{\mathrm{flu}}=371 \mathrm{~nm}$.
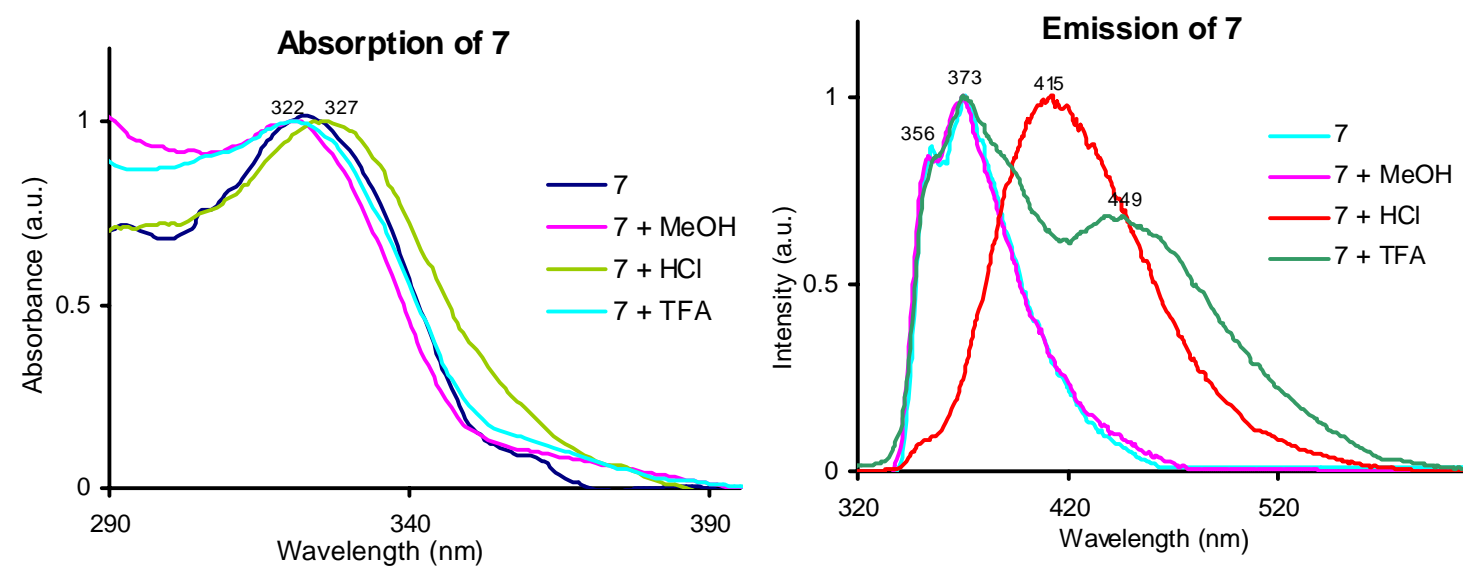

Figure 1. Absorption and emission spectra of polymer 7 in chloroform. Emission is recorded upon addition of methanol, $\mathrm{HCl}$ and trfluoroacetic acid to the solution of $\mathbf{7}$ in chloroform.

Polymer 8: $0.137 \mathrm{~g}\left(80 \%\right.$, oligomers mixture), yellow solid. ${ }^{1} \mathrm{H}$ NMR $\left(\mathrm{CDCl}_{3}\right): \delta 8.17(\mathrm{~s}, 2 \mathrm{H})$, 8.10, 8.08, (2s, 2H), 7.99 (d, $\left.\mathrm{J}_{\mathrm{HH}}=7.8 \mathrm{~Hz}, 2 \mathrm{H}\right), 7.88(\mathrm{~m}, 7.8 \mathrm{~Hz}, 2 \mathrm{H}), 7.60,7.47,7.40(3 \mathrm{~s}, 2 \mathrm{H})$, , $4.16(\mathrm{~s} 2 \mathrm{H}), 3.28$ (s, acetylene-H), 2.79 (bm, $8 \mathrm{H}), 1.56(\mathrm{bm}, 6 \mathrm{H}), 1.25$ (bs 54H), $0.86(\mathrm{bs}, 18 \mathrm{H})$; ${ }^{13} \mathrm{C}$ NMR (solid-state): $\delta=145.3,139.4,135.1,126.6,119.0,65.8,60.3,53.4,36.5,28.6,24.4$, 13.4, 9.8; IR: v 3439, 3306, 3130, 2957, 2924, 2101, 1616, 1589, 1483,1460, 1259, 1221, 1095, 1040, 1011, 816; GPC (polystyrene standards): $\mathrm{Mn}=1975, \mathrm{Mw} / \mathrm{Mn}=2.1, \mathrm{Pn}=3.3 ; \Phi_{\mathrm{F}}=0.41 ; \lambda$ $\max _{\mathrm{abs}}=322, \lambda \max _{\mathrm{flu}}=370$.
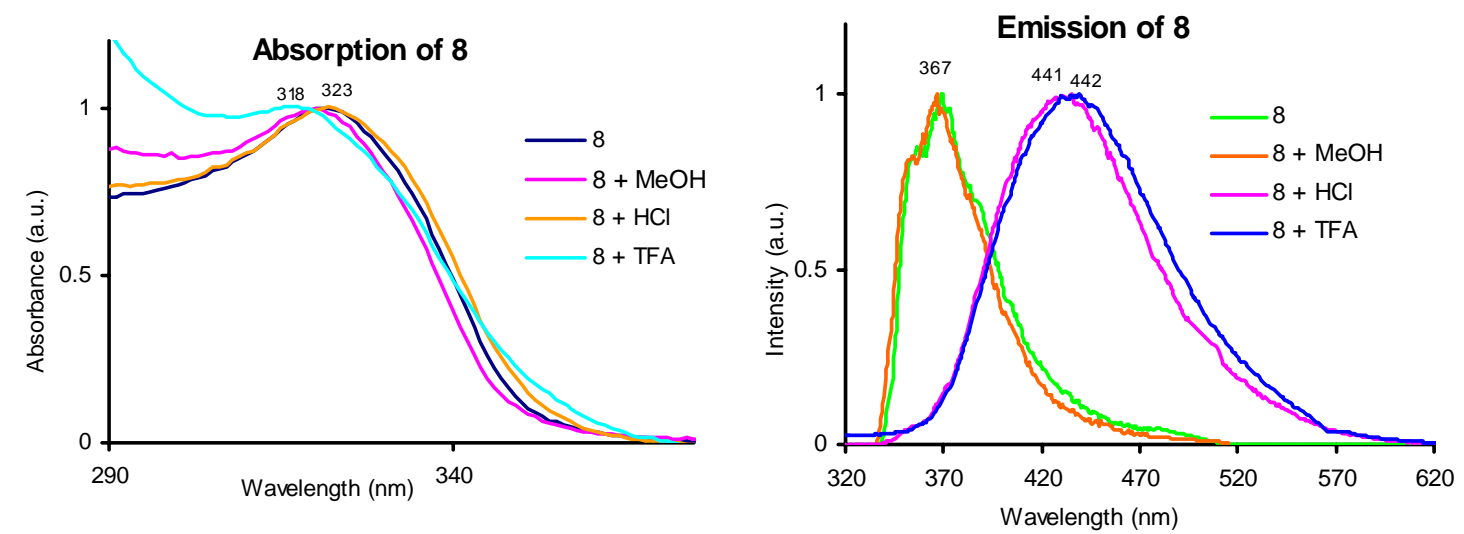

Figure 2. Absorption and emission spectra of polymer 8 in chloroform. Emission is recorded upon addition of methanol, $\mathrm{HCl}$ and trfluoroacetic acid to the solution of $\mathbf{8}$ in chloroform.

Polymer 9: $0.261 \mathrm{~g}(92 \%)$, yellow solid. H NMR $\left(\mathrm{CDCl}_{3}\right): \delta 8.20(\mathrm{~s}, 2 \mathrm{H}), 7.90(\mathrm{bs}, 2 \mathrm{H}), 7.82$ (bs, 2H), 7.70 (bs), 7.26 (s, 2H), 2.94, 2.14, 2.04, 1.72, 1.25, 0.86 (6 bs, alkyl chains); ${ }^{13} \mathrm{C}$ NMR 
$\left(\mathrm{CDCl}_{3}\right): \delta 153.4,148.1,140.5,138.9,136.8,131.4,129.5,121.3,119.6,115.6,56.5,56.1,40.6$, 33.8, 32.2, 31.6, 29.9, 24.2, 24.0, 22.9, 14.3; IR: v 3433, 2953, 2918, 2849, 2104, 1612, 1470, 1377, 1296, 1227, 1034, 1011, 889, 812, 717; GPC (polystyrene standards): $\mathrm{Mn}=5693, \mathrm{Mw} / \mathrm{Mn}$ $=2.2, \mathrm{Pn}=5.4 ; \Phi_{\mathrm{F}}=0.38 ; \lambda \max _{\mathrm{abs}}=329, \lambda \max \mathrm{flu}=376-358$.
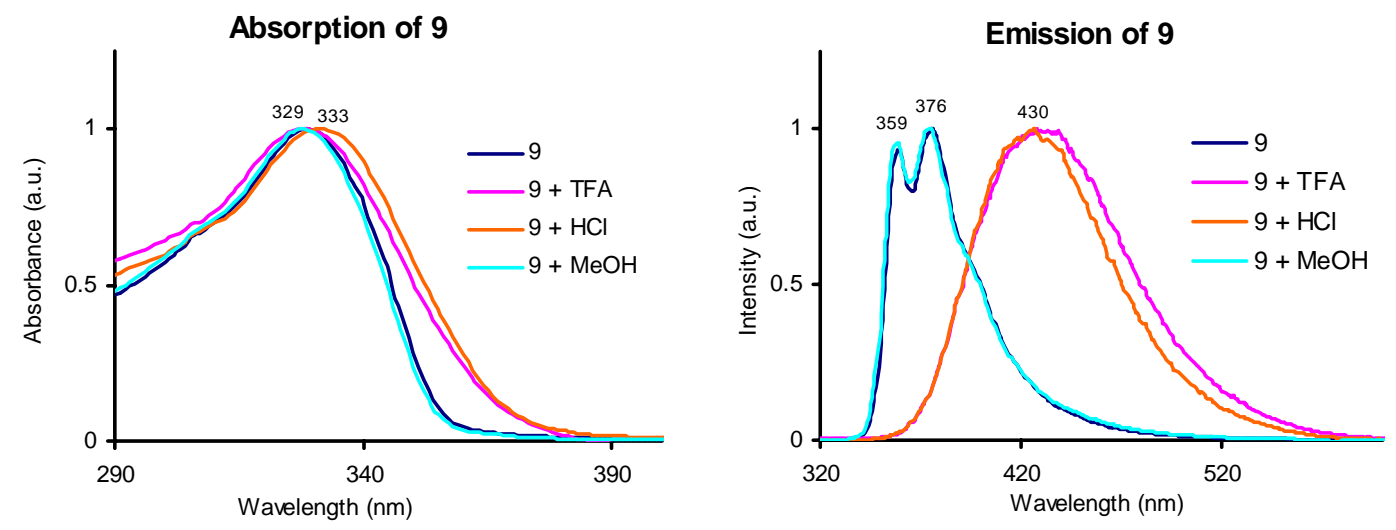

Figure 3. Absorption and emission spectra of polymer 9 in chloroform. Emission is recorded upon addition of methanol, $\mathrm{HCl}$ and trfluoroacetic acid to the solution of $\mathbf{9}$ in chloroform.

Polymer 10: $0.278 \mathrm{~g}(87 \%)$, off-white solid. ${ }^{1} \mathrm{H}$ NMR $\left(\mathrm{CDCl}_{3}\right): \delta 8.20(\mathrm{~s}, 2 \mathrm{H}), 7.93$ (bs, $\left.2 \mathrm{H}\right)$, 7.81 (bs, 2H), 7.60 (bs, 2H), $7.26(\mathrm{~s}, 2 \mathrm{H}), 2.90,2.12,1.59,1.17,0.82$ (5 bs alkyl chains); ${ }^{13} \mathrm{C}$ NMR $\left(\mathrm{CDCl}_{3}\right): \delta 153.3,148.3,140.6,138.1,136.9,132.8,129.9,121.4,120.2,119.6,115.6$, 56.5, 40.7, 40.4, 37.7, 32.6, 32.1, 30.2, 29.7, 29.5, 28.9, 25.8, 24.2, 23.3, 22.9, 14.3, 11.0; IR: v 3452, 2953, 2924, 2852, 2106, 1614, 1473, 1464, 1377, 1225, 1036, 1011, 820, 727; GPC (polystyrene standards): $\mathrm{Mn}=8753, \mathrm{Mw} / \mathrm{Mn}=5.80, \mathrm{Pn}=9.4 ; \Phi_{\mathrm{F}}=0.48 ; \lambda \max { }_{\mathrm{abs}}=328, \lambda \max$ $\mathrm{flu}=375-358$.
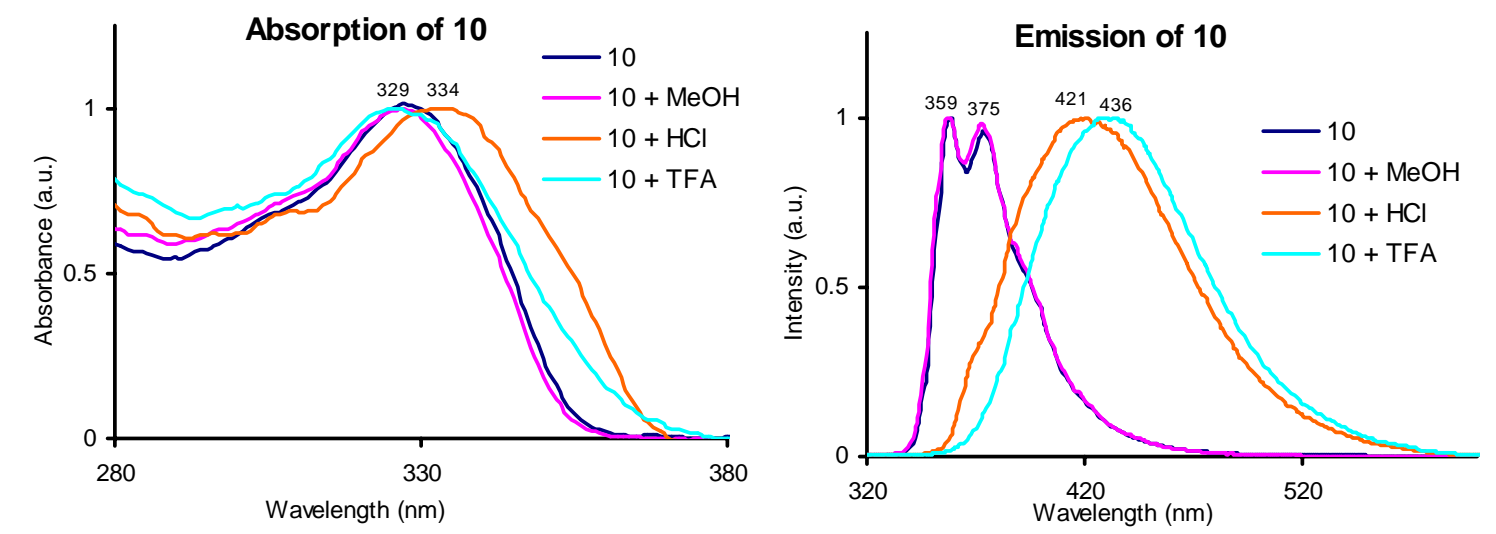

Figure 4. Absorption and emission spectra of polymer 7 in chloroform. Emission is recorded upon addition of methanol, $\mathrm{HCl}$ and trfluoroacetic acid to the solution of 7 in chloroform.

Polymer 11: $0.220 \mathrm{~g}(86 \%)$, insoluble red-brown solid. ${ }^{13} \mathrm{C}$ NMR (solid-state): $\delta=148.7,144.9$, 137.5, 127.1, 123.7, 109.0, 53.5, 41.4, 29.6, 22.7, 13.8; IR: v 3431, 2940, 2662, 2119, 1628, $1458,1244,1205,1034,936,845,808,722 ; \Phi_{\mathrm{F}}=0.22 ; \lambda \max _{\mathrm{abs}}=314, \lambda \max _{\mathrm{flu}}=379$. 
Polymer 12: $0.161 \mathrm{~g}(88 \%)$, off-white solid. ${ }^{1} \mathrm{H}$ NMR $\left(\mathrm{CDCl}_{3}\right): \delta 8.35(\mathrm{~s}, 2 \mathrm{H}), 8.07\left(\mathrm{~d}, \mathrm{~J}_{\mathrm{HH}}=\right.$ $7.8 \mathrm{~Hz}), 7.66(\mathrm{~s}, 2 \mathrm{H}), 7.42\left(\mathrm{~d}, \mathrm{~J}_{\mathrm{HH}}=7.8 \mathrm{~Hz}\right), 7.36(\mathrm{~s}, 2 \mathrm{H}), 4.04(\mathrm{~s}, 6 \mathrm{H}), 2.87,1.61,1.25,0.82(4$ bs, alkyl chains); ${ }^{13} \mathrm{C}$ NMR $\left(\mathrm{CDCl}_{3}\right): \delta=151.3,146.9,142.2,137.7,132.4,130.1,126.4,125.8$, 124.1, 120.5, 111.4, 56.6, 40.3, 37.8, 32.6, 28.9, 25.8, 23.4, 14.5, 11.0; IR: v 2955, 2928, 2856, $2120,1607,1578,1508,1460,1381,1319,1250,1220,1182,1140,1095,1030,984,810$; GPC (polystyrene standards): $\mathrm{Mn}=1835, \mathrm{Mw} / \mathrm{Mn}=7.5, \mathrm{Pn}=8.0 ; \Phi_{\mathrm{F}}=0.48 ; \lambda \max { }_{\mathrm{abs}}=314, \lambda \max$ $\mathrm{flu}=379$.
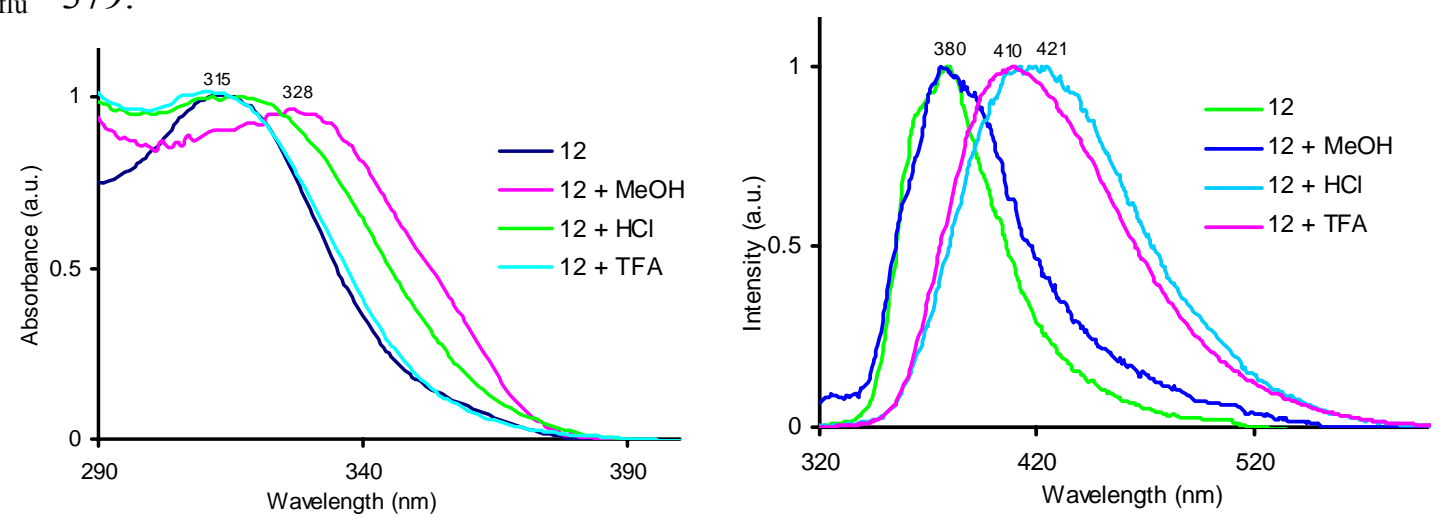

Figure 5. Absorption and emission spectra of polymer 12 in chloroform. Emission is recorded upon addition of methanol, $\mathrm{HCl}$ and trfluoroacetic acid to the solution of $\mathbf{1 2}$ in chloroform.

Polymer 13: $0.161 \mathrm{~g}(88 \%)$, off-white solid. ${ }^{1} \mathrm{H}$ NMR $\left(\mathrm{CDCl}_{3}\right): \delta 8.35(\mathrm{~s} 2 \mathrm{H}), 8.07\left(\mathrm{~d}, \mathrm{~J}_{\mathrm{HH}}=7.8\right.$ $\mathrm{Hz}), 7.66(\mathrm{~s}, 2 \mathrm{H}), 7.42\left(\mathrm{~d}, \mathrm{~J}_{\mathrm{HH}}=7.8 \mathrm{~Hz}\right), 7.36(\mathrm{~s}, 2 \mathrm{H}), 4.04(\mathrm{~s}, 6 \mathrm{H}), 2.87,1.61,1.25,0.82(4 \mathrm{bs}$, alkyl chains); ${ }^{13} \mathrm{C}$ NMR $\left(\mathrm{CDCl}_{3}\right): \delta=151.3,146.9,142.2,137.7,132.4,130.1,126.4,125.8$, $124.1,120.5,111.4,56.6,40.3,37.8,32.6,28.9,25.8,23.4,14.5,11.0$; IR: v 2955, 2928, 2856, $2120,1607,1578,1508,1460,1381,1319,1250,1220,1182,1140,1095,1030,984,810$; GPC (polystyrene standards): $\mathrm{Mn}=1835, \mathrm{Mw} / \mathrm{Mn}=70.54, \mathrm{Pn}=8.0 ; \Phi_{\mathrm{F}}=0.48 ; \lambda \max _{\mathrm{abs}}=314, \lambda \max$ $\mathrm{flu}=379$.
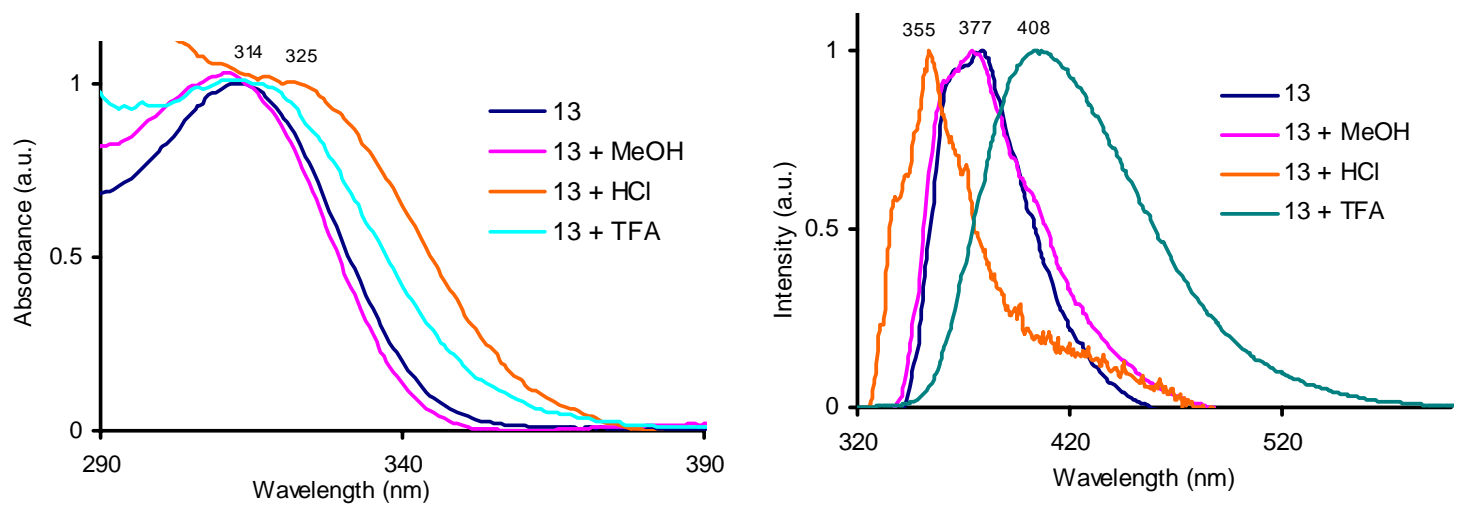

Figure 6. Absorption and emission spectra of polymer $\mathbf{1 3}$ in chloroform. Emission is recorded upon addition of methanol, $\mathrm{HCl}$ and trfluoroacetic acid to the solution of $\mathbf{1 3}$ in chloroform. 

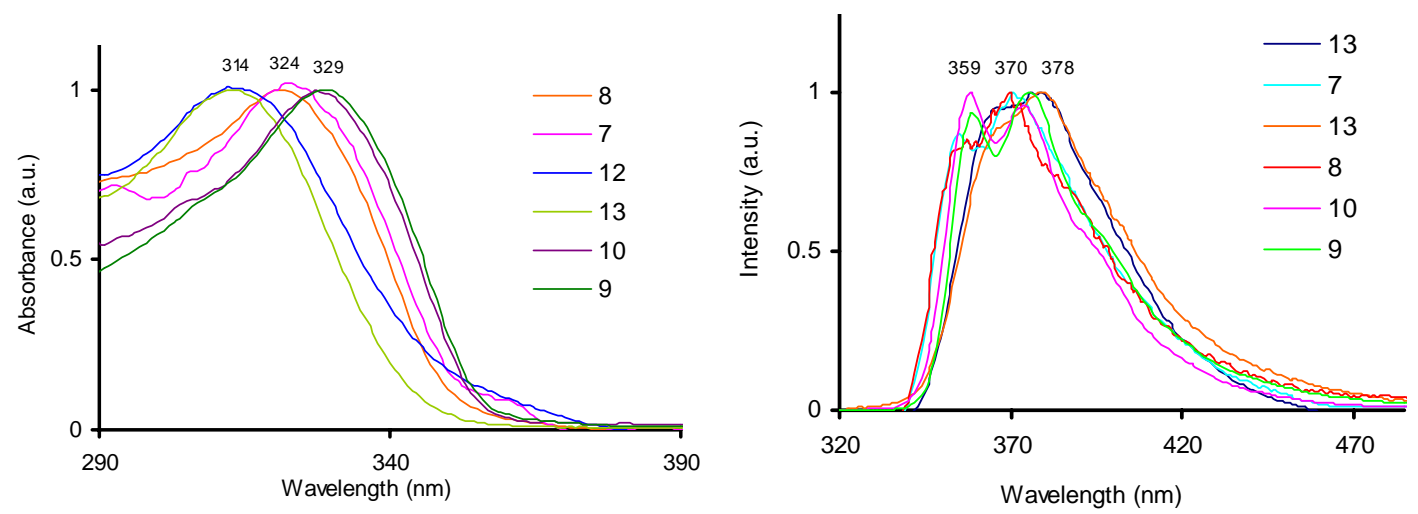

Figure 7. UV-vis and emission spectra of polymers 7-12

\section{Film making and Annealing}

0.3-0.5 mM solutions were prepared from a combination of diazides $\mathbf{1 , 7}$ and diynes 2 in chloroform. A Headway Research Model PWM32 instrument was used to spin-coat dilute chloroform solutions of mixed monomers onto glass slides for thin film experiments. Spincoating formed $80-100 \mathrm{~nm}$ thick films on a glass slide. These films were annealed in pre-heated oven at $170{ }^{\circ} \mathrm{C}$ for $1 \mathrm{~h}$. The films of mixed monomers were used for AFM measurements.

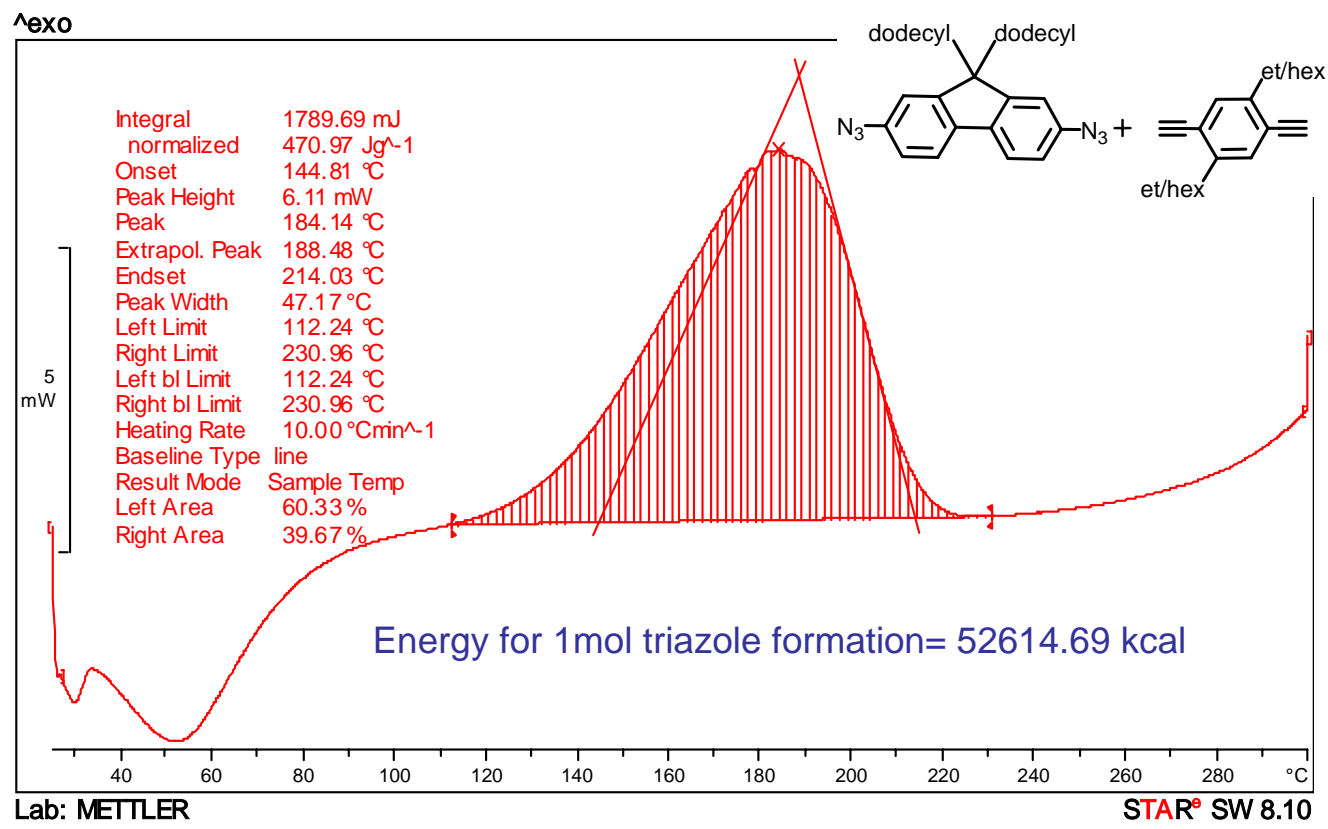

Figure 8. DSC Data for the formation of polymer 10 (in main ms. polymer 6)

\section{Heated Cantilever AFM Measurements}

The heated atomic force microscope (AFM) cantilevers were made in our group at Georgia Tech, and are similar to those developed for data storage. ${ }^{3}$ The cantilevers were fabricated from doped, single-crystal silicon and were fabricated using a standard silicon-on-insulator microcantilever fabrication process. 

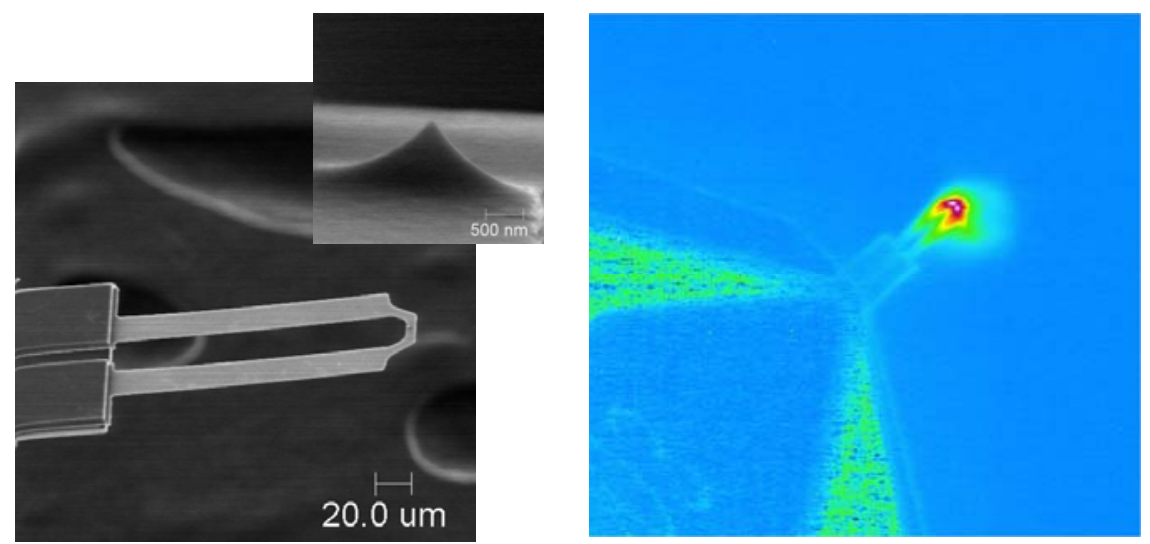

Figure 9. AFM cantilevers with integrated heaters fabricated at Georgia Institute of Technology. Left: Scanning electron microscope images. The cantilever is in the shape of a "U" so that it can carry electrical current in a continuous circuit. This cantilever has a tip with radius of curvature $<50 \mathrm{~nm}$. Right: infrared microscope image of a cantilever during steady-state heating. The heating occurs primarily at the free end of the cantilever.

The cantilever temperature is a function of its electrical resistance, allowing precision temperature calibration.

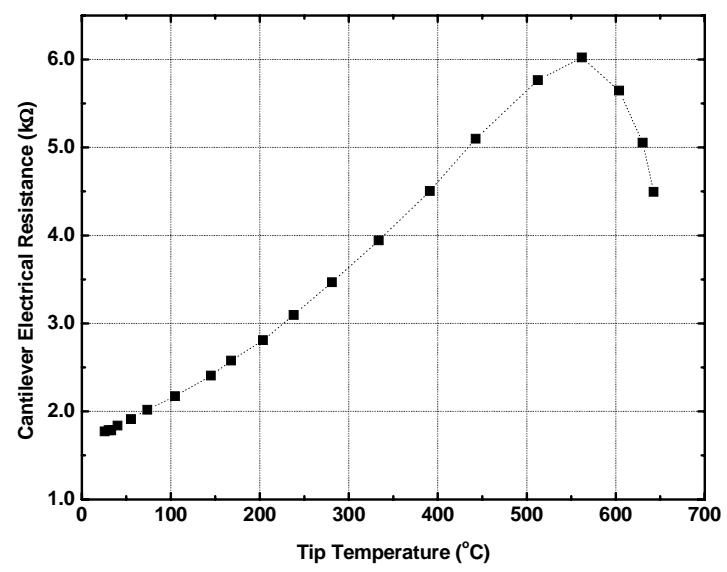

Figure 10. Cantilever temperature calibration. The cantilever has a highly nonlinear temperature coefficient of electrical resistance. Using laser raman thermometry it is possible to calibrate the cantilever temperature to within $1{ }^{\circ} \mathrm{C}$.

\section{Quantum Chemical Calculations}

Calculations were performed on the two model compounds using Spartan Pro (Wavefunction) as implemented on a Dell Personal Computer. The calculations were performed on the B3LYP-G$31 \mathrm{G}^{* *}$ level using B3LYP-G-31G** optimized geometries. The localization of either HOMO or LUMO is clearly visible in the two model compounds. 
Calculations on model compound $\mathbf{M 1}$

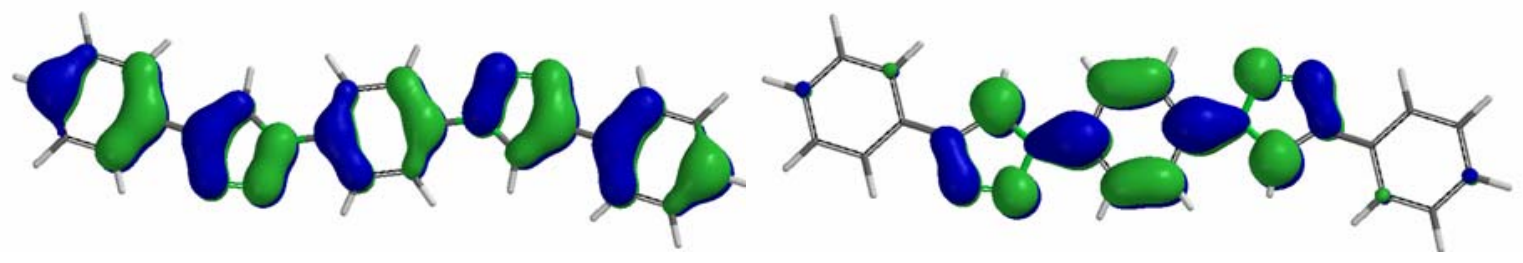

Figure 11. Left: HOMO of model compound; Right LUMO of model compound

Calculation on Model Compound M2
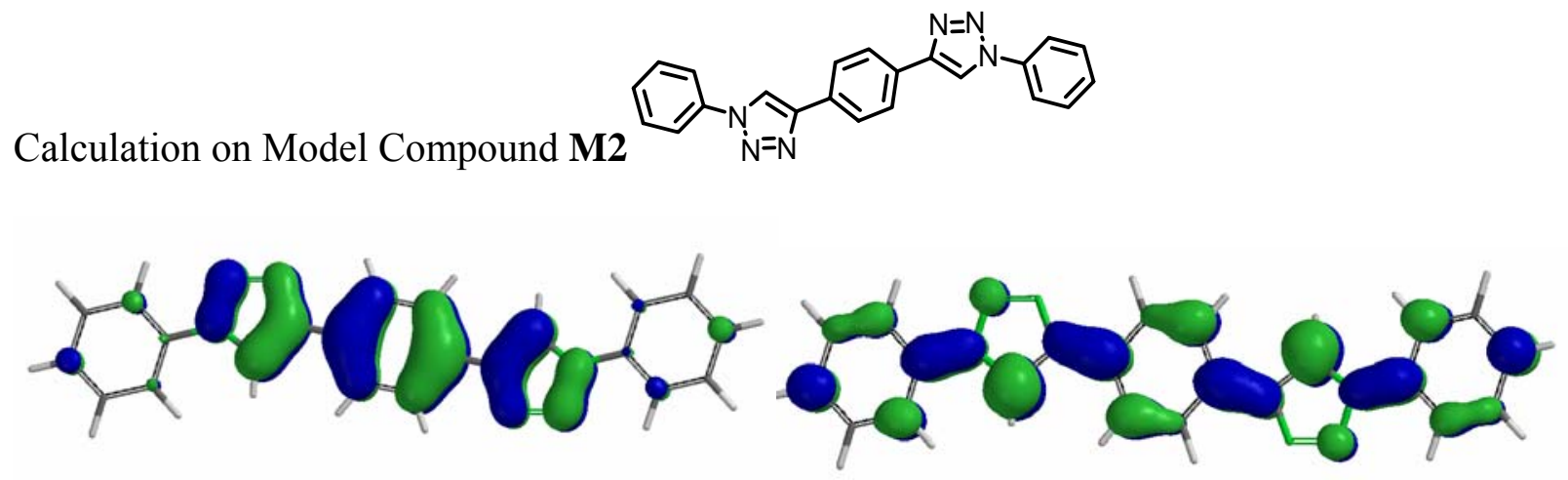

Figure 12. Left: HOMO of model compound M2; Right LUMO of model compound M2

\section{References:}

1. Soloducho, J.; Roszak, S.; Chyla, A.; Tajchert, K., New Journal of Chemistry 2001, 25(9), $1175-1181$.

2. Itaya A.; Inoue T.; Yamamoto T.; Nobutou T.; Miyasaka H.; Toriumi M.; Ueno T., J. Mater. Chem, 1996, 6, 705-710.

3. King, W. P.; Kenny, T. W.; Goodson, K. E.; Cross, G.; Despont, M.; Durig, U.; Rothuizen, H.; Binnig, G. K.; Vettiger, P., Atomic force microscope cantilevers for combined thermomechanical data writing and reading. Applied Physics Letters 2001, 78 , 1300-1302. 